\title{
Article
}

\section{A Needs-Based Augmented Reality System}

\author{
Manal A. Yahya *(D) and Ajantha Dahanayake \\ School of Engineering Sciences, Lappeenranta-Lahti University of Technology, Yliopistonkatu 34, \\ 53850 Lappeenranta, Finland; ajantha.dahanayake@lut.fi \\ * Correspondence: manal.yahya@student.lut.fi
}

\begin{abstract}
Augmented Reality aims to enhance the real world with computer-generated information. AR technology is both attractive and promising. Current AR experiences depend on external elements to launch, such as markers, images, and location. For an AR experience to be more personalized, this research proposes a scheme to trigger AR experiences based on human needs. This approach should enable human needs to be captured, and analyze them to select the most suited experiences that fulfill or aids in fulfilling needs. The contribution of this paper includes (1) a study of current AR technologies and triggers, (2) an analysis of human needs into measurable elements, and (3) a description of a needs-based AR application process with a demonstration of the process guidelines. The research presents a proof of concept prototype of a restaurant that satisfies the subsistence need for hunger. The results show the effectiveness of the guidelines in detecting human needs and recommending AR experiences; however, producing correct predictions and recommendations requires a well-established dataset.
\end{abstract}

Keywords: conceptual model; augmented reality; human needs; experience trigger

check for updates

Citation: Yahya, M.A.; Dahanayake, A. A Needs-Based Augmented Reality System. Appl. Sci. 2021, 11, 7978. https://doi.org/10.3390/app11177978

Academic Editor: Youngho Lee

Received: 18 July 2021

Accepted: 17 August 2021

Published: 28 August 2021

Publisher's Note: MDPI stays neutral with regard to jurisdictional claims in published maps and institutional affiliations.

Copyright: (c) 2021 by the authors. Licensee MDPI, Basel, Switzerland. This article is an open access article distributed under the terms and conditions of the Creative Commons Attribution (CC BY) license (https:// creativecommons.org/licenses/by/ $4.0 /)$.

\section{Introduction}

A classical survey on augmented reality (AR) describes it as "AR supplements reality rather than completely replacing it" [1].

Augmented Reality (AR) is a technology that enhances a real environment with computer-generated information using different sensory modalities, including visual, auditory, haptic, and olfactory. AR aims to simplify users' lives by bringing virtual information to their attention [2]. An Augmented Reality (AR) system embodies the following properties [3]:

- Enhances real environments by adding virtual objects.

- Works in real-time and provides interactivity.

- Provides the correct placement of virtual objects within the environment.

AR has many application areas such as education and learning [4], entertainment and gaming [5], food and beverage industry [6], health care [7], manufacturing [8], museums [9], space exploration [10], and tourism [11].

The study of augmented reality incorporates many computing areas such as tracking, interaction, display, mobile AR, authoring, visualization, calibration, and rendering [12]. AR literature focuses on the development of the technology components; however, little attention is devoted to examining personalized experiences. This research aims to enrich augmented reality paradigms by developing a novel AR experience trigger: a needs trigger. Despite the importance of needs and their satisfaction in human life, there is still a shortage of incorporating human needs in information systems and tools [13]. Augmented reality is a growing field that may benefit from the use of human needs. Similar to the present location, markers, and image recognition triggers, a basic human need may be used to activate a more personalized experience.

This research makes several contributions: (1) study augmented reality classifications and triggers; (2) analyze human needs and transfer them into sensible data elements; and (3) present the human needs trigger framework and guidelines for augmented reality. 
The following sections discuss the state-of-the-art in the different types of AR, provide a discussion of the proposed framework and guidelines, and finally, demonstrate and discuss the use of this approach for creating needs-based AR experiences.

\section{Background}

Augmentation is described in previous literature according to human senses [14]; there is visual, auditory, and tactile augmentation. Each of these is used for a particular goal and requires different hardware. This section presents a literature study on AR.

\subsection{Technologies in Augmented Reality}

It is essential to understand the general process in an AR system, to realize where each of the technologies fits and how they function together. This section provides definitions for the various topics and technologies supporting the AR process [15] (Figure 1).

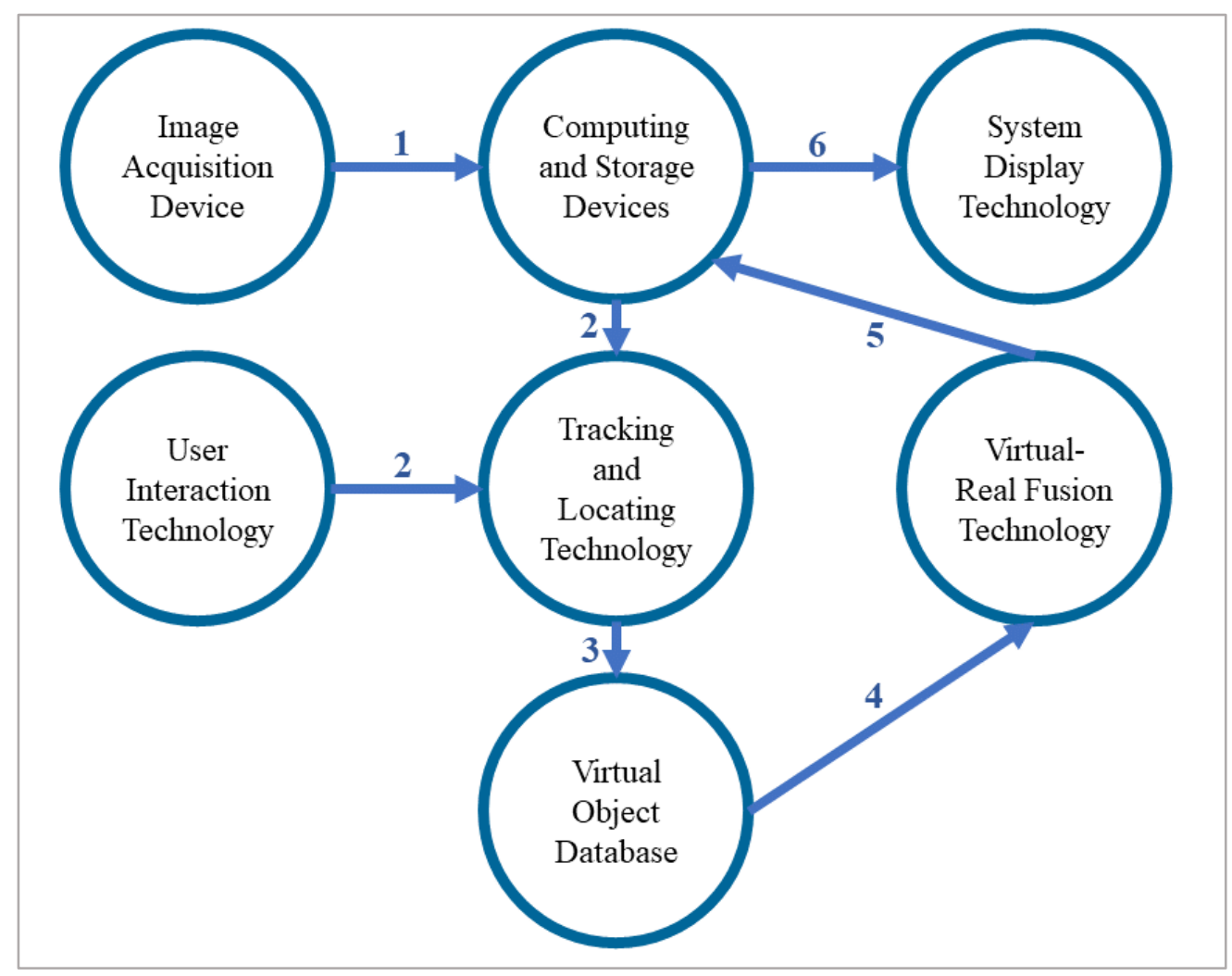

Figure 1. General process in an augmented reality system.

The components in a vision-based AR process include:

- Image acquisition device: this device, usually a camera, captures the marker or object to be recognized.

- Computing and storage device: the component responsible for processing the gathered input and producing the correct output.

- Tracking and location technology: tracks the user position, view direction, and motion to decide on the virtual object to display.

- User interaction technology: the interface that captures the user input.

- Virtual object database: a database that includes relevant virtual objects.

- Virtual-real fusion technology: combines the virtual objects and real environment to ensure correct occlusion, shadows, and illumination.

- System display technology: the display technology presents the augmented information integrated with the real environment. The display technology depends on the type of AR system, visual, auditory, haptic, etc. 
The general process starts by acquiring an image from the real world and sending it to computing and storage devices. This image and user interaction gestures are sent to the tracking technology, which decides what virtual information to display based on the user's position, viewing direction, and state of motion. The virtual information is retrieved from the virtual objects database and sent to the fusion technology that ensures proper object registration in the real world. The virtual information is then displayed using the display technology [15]. Table 1 provides definitions for the core AR technologies that remain popular research topics: tracking, interaction and user interfaces, calibration and registration, display techniques, and AR applications [16].

Table 1. Core augmented reality technologies and techniques [16].

\begin{tabular}{cc}
\hline Core AR Technology & Definition \\
\hline $\begin{array}{c}\text { Tracking techniques } \\
\text { Interaction techniques and user } \\
\text { interfaces }\end{array}$ & $\begin{array}{c}\text { "Methods of tracking a target object/environment via } \\
\text { cameras and sensors, and estimating viewpoint poses". } \\
\text { "Techniques and interfaces for interacting with virtual } \\
\text { content". }\end{array}$ \\
Calibration and registration & $\begin{array}{r}\text { "Geometric or photometric calibration methods, and method } \\
\text { to align multiple coordinate frames". }\end{array}$ \\
Display techniques & "Display hardware to present virtual content in AR, including \\
head-worn, handheld, and projected displays". & "AR systems in application domains such as medicine, \\
manufacturing, or military, among others".
\end{tabular}

While Table 1 describes the core AR technologies in a general manner, these technologies differ with the type of AR used. For example, the tracking techniques for vision-based AR use a camera to identify markers, while the tracking techniques for auditory AR uses acoustic tracking systems that analyze sound waves [17].

\subsection{Classification of Augmented Reality}

There are different types of AR systems and apps depending on the concepts and technology. The classification of these types is not unified; different research papers classify the types differently. Edwards-Stewart, Hoyt, and Reger [18] describe six types of AR under two main categories: triggered and view-based augmentation. The triggered AR technologies include marker-based AR, location-based AR, dynamic augmentation, and complex augmentation. The view-based augmentation includes Indirect and non-specific digital augmentations. Table 2 describes the classification mentioned above.

Table 2. Classification of augmented reality types [18].

\begin{tabular}{|c|c|c|c|}
\hline Category & Type & Brief & Example \\
\hline \multirow{5}{*}{ Triggered } & & Triggered by a marker: & \\
\hline & Marker-Based & Paper (image) & Museum displays \\
\hline & & Physical object & \\
\hline & Location-Based & Triggered by GPS location & Monocle Restaurant information \\
\hline & Dynamic Augmentation & Responsive to object changes & $\begin{array}{l}\text { Digitally trying clothes and accessories with } \\
\text { shopping apps }\end{array}$ \\
\hline \multirow{3}{*}{ View-Based } & Complex Augmentation & A combination of the above & $\begin{array}{c}\text { Dynamic view with digital information from } \\
\text { the Internet }\end{array}$ \\
\hline & Indirect Augmentation & Intelligent augmentation of a static view & Taking a picture and changing the wall color \\
\hline & $\begin{array}{l}\text { Non-Specific digital } \\
\text { Augmentation }\end{array}$ & Augmentation of a dynamic view & $\begin{array}{l}\text { Augmentation in } \\
\text { mobile games }\end{array}$ \\
\hline
\end{tabular}

Other classifications divide AR into marker-based, marker-less, outlining AR, and superimposition AR. The marker-based type of AR depends on a marker that, when scanned by a camera, triggers an AR experience. The marker may be an image, a fiducial marker (Figure 2), or a physical object. 


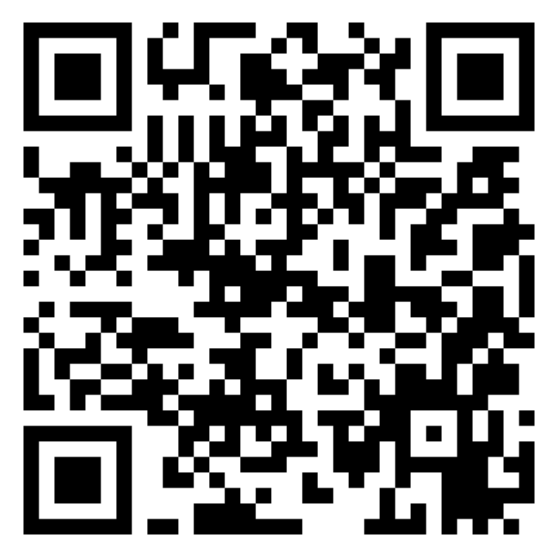

Figure 2. Fiducial marker.

Markerless AR does not require markers; it uses other triggers such as location-based $\mathrm{AR}$. The projection-based AR is also markerless and works by projecting digital information on objects in the user's environment. Outlining AR uses the special abilities of cameras in recognizing objects in conditions that may be difficult to recognize for the eyes and provide guidance in the form of outlines on objects. Superimposition AR recognizes objects and superimposes virtual information on them. It includes face filters as done by Instagram and Snapchat.

AR spans beyond the visual augmentations to include the natural senses of hearing, touch, taste, and smell forming the auditory, haptic, gustatory, and olfaction AR systems respectively. This variety in AR systems constitutes another classification based on the senses.

Auditory AR is the second most common class after visual AR. It embeds auditory content into a user's acoustic environment. In many cases, the sound is integrated with visual AR to enhance it, while in others it is used as the main augmentation to support visually impaired individuals [19].

Haptic AR is an underexplored type of AR, it "enables the user to feel a real environment augmented with synthetic haptic stimuli" [20]. Jeon and Choi [20] provide a comparison between visual and haptic AR as shown in Table 3.

Table 3. Computational procedures of visual and haptic AR [20].

\begin{tabular}{|c|c|c|}
\hline Procedure & Visual AR & Haptic AR \\
\hline $\begin{array}{l}\text { Sensing a real } \\
\text { environment }\end{array}$ & $\begin{array}{l}\text { Captures real information needed for visual } \\
\text { augmentation }\end{array}$ & $\begin{array}{l}\text { Senses real information needed for haptic } \\
\text { augmentation }\end{array}$ \\
\hline Sensor examples & Camera, range finder, tracker & $\begin{array}{l}\text { Position encoder, accelerometer, force sensor, } \\
\text { thermometer }\end{array}$ \\
\hline $\begin{array}{l}\text { Constructing stimuli } \\
\text { for augmentation }\end{array}$ & $\begin{array}{l}\text { 1. Real-virtual registration } \\
\text { 2. Overlay of the virtual object on the real scene }\end{array}$ & $\begin{array}{l}\text { 1. Contact detection between the tool and a real object } \\
\text { 2. Modulation of real haptic stimuli }\end{array}$ \\
\hline $\begin{array}{l}\text { Displaying } \\
\text { augmented stimuli }\end{array}$ & Uses a visual display & Uses a haptic display \\
\hline Display examples & Head-mounted display, projector, mobile phone & $\begin{array}{l}\text { Force-feedback interface, tactile display, thermal } \\
\text { display }\end{array}$ \\
\hline
\end{tabular}

On the other hand, gustatory AR is related to the sense of taste and is concerned with embedding gustatory information into human-computer interaction [21]. This type of AR research is limited because of its complexity since the sense of taste depends on different factors including vision, olfaction, and memories [21].

An olfaction AR system focuses on the sense of smell and has an olfactory display to produce odor in a gaseous or liquid state to the user [22]. 


\subsection{Review of Exiting Platforms}

This section provides a summary of prominent AR platforms. These platforms offer complete AR-experience creation capabilities. The focus is on how the different experiences are triggered. Table 4 summarizes the types of experiences and triggers of the prominent AR platforms, AWE (Augmented Web Experiences), Zap Works, BlippAR, Spark AR, Wikitude, and Unity AR.

Table 4. Comparison of AR platforms with types and triggers.

\begin{tabular}{|c|c|c|c|c|}
\hline Platform & $\begin{array}{l}\text { Publish Application } \\
\text { or Web-Based }\end{array}$ & SDK & $\begin{array}{c}\text { Types of } \\
\text { Experiences }\end{array}$ & Experience Trigger, AR-type \\
\hline $\begin{array}{c}\text { AWE Media Studio } \\
\text { https:/ / awe.media/ } \\
\text { (accessed on } 18 \text { August 2021). } \\
\text { Zap Works }\end{array}$ & Web & No & $\begin{array}{l}\text { Image, spatial, face tracking, } \\
\text { GPS location, } 360^{\circ}\end{array}$ & $\begin{array}{l}\text { Weblink, } \\
\text { Non-specific digital } \\
\text { augmentation }\end{array}$ \\
\hline $\begin{array}{c}\text { https:/ / zap.works / } \\
\text { (accessed on } 18 \text { August 2021). } \\
\text { BlippAR Builder }\end{array}$ & Either & Yes & Image, face tracking, $360^{\circ}$ & Marker-based (special marker) \\
\hline $\begin{array}{l}\text { https: / / www.blippar.com/build-ar } \\
\text { (accessed on } 18 \text { August 2021). }\end{array}$ & Either & Yes & Image & Marker-based (image scan) \\
\hline $\begin{array}{c}\text { Spark AR Studio } \\
\text { https: / / sparkar.facebook.com/ar-studio/ } \\
\text { (accessed on } 18 \text { August 2021). }\end{array}$ & $\begin{array}{l}\text { On Facebook or } \\
\text { Instagram }\end{array}$ & No & Face tracking, image-based & $\begin{array}{l}\text { Maker-based, dynamic } \\
\text { augmentation }\end{array}$ \\
\hline $\begin{array}{l}\text { Wikitude AR } \\
\text { https: / / www.wikitude.com/ } \\
\text { (accessed on } 18 \text { August 2021). }\end{array}$ & Application & Yes & $\begin{array}{l}\text { Image, object, scene } \\
\text { recognition, instant tracking, } \\
\text { Geo AR }\end{array}$ & $\begin{array}{l}\text { Marker-based, location-based, } \\
\text { dynamic augmentation }\end{array}$ \\
\hline $\begin{array}{c}\text { Unity MARS } \\
\text { https:/ / unity.com/products/ unity-mars } \\
\text { (accessed on } 18 \text { August 2021). }\end{array}$ & Application & No & Location-aware, context-aware & $\begin{array}{l}\text { Marker-based, complex } \\
\text { augmentation }\end{array}$ \\
\hline
\end{tabular}

As is clear from the summary above, marker-based AR is the most used type with image and object recognition. While most platforms enable generic experience creation, some offer face tracking, location-based, and context-aware capabilities allowing for customized experiences.

\subsection{Triggers}

From the previous sections, we observe the variety of AR triggers. Triggers in AR are "stimuli or characteristics that initiate or trigger the augmentation" [18]. Currently, the top starters of an AR experience are markers, images, physical objects, scene recognition, movement, location, and sometimes the choice to load an experience. In some instances, an experience may be initiated by multiple separate triggers [23].

In the future, it is expected that more advanced forms of triggers will be used in augmented reality, such as sound or voice recognition, temperature, smell, and gesture [23].

\section{Theoretical Framework}

This research proposes the hypothesis, "With advancing sensor technology, basic human needs are viable triggers for augmented reality experiences". The goal is to create a novel paradigm and provide developers with more options to personalize AR experiences. This section describes the conceptual basis leading to and supporting the hypothesis.

\subsection{Personalization in Augmented Reality}

In many cases, $A R$ is used to enhance the user experience in museums and tourism $[24,25]$, education [26,27], entertainment, and medicine by adding digital information to the real environment. These approaches usually focus on the experience and the object requiring enhancement. Another way to conceive experiences is to concentrate on the user/users viewing them. This is the concept of personalization, defined as "a process that changes the functionality, interface, information access, and content, or distinctiveness of a system to increase its relevance to an individual or a category of individuals" [28]. The core elements of personalization definitions are: 
- "a purpose or goal of personalization".

- "What is personalized". Four aspects of information systems may be personalized: the information (content), the presentation of information (user interface), the delivery method (channel), and the action.

- "The target of personalization". The target can be a group of individuals or a specific individual.

Personalization enables users to acquire information specific to their "needs, goals, knowledge, interests or other characteristics" [29]. Studying the types of AR experiences in literature, three primary levels of personalization are evident. The first level is generic experiences in which no personalization is implemented. The AR experience displays the same information to all viewers at any time, such as in museum displays. The second personalization level includes experiences receptive to external factors such as location and context $[30,31]$. The third level displays information about a specific user. An example of this is SentiAR (https:/ / sentiar.com/) (accessed on 18 August 2021) an AR experience about a patient in a surgery room or an AccuVein (https://www.accuvein.com/) (accessed on 18 August 2021) device enabling the view of a patient vein in blood sampling.

This research aims to formulate a roadmap that embeds human needs in AR experiences to enhance experience personalization. In this sense, personalization elements are defined as:

- Purpose: to trigger AR experiences based on user needs

- What is personalized: the display of experience according to need

- Target: the user viewing the AR experience

- The following sections explain how these elements are applied in the proposed system.

\subsection{Human Needs in Pervasive Environments}

The satisfaction of human needs is a core value in pervasive environments. The study of needs in computing has been around for some time now. This topic is addressed from many viewpoints:

- Needs representation: Some scholars attempted to represent human needs using ontologies [13,32], others used directed graphs [33].

- Human needs are identified in several methods: interviews, questionnaires, signal processing on brain scans, and prediction methods that depend on sentiment analysis.

- From the literature study, it is clear that technology may provide need satisfaction by different means, including providing services, social media use $[34,35]$, internet and mobile use, online relationships, video games, and gamification.

\subsection{Proposed Concept}

As there are different types of AR experiences with different triggers, this research proposes to add a new type, which is a Needs-based AR. For a Needs-Based AR system, a basic human need triggers and starts the AR experience. Manfred Max-Neef's model [36] provides a guide for the categorization of needs in his research. A detailed analysis will enable knowledge about the required sensors for the different needs and the logic necessary to transform sensor data into definite needs. Figure 3 depicts the layers of functionality in the proposed system. The first step is to collect sensor data, then applying the correct logic, this data is transformed into an identifiable need. Based on the identified need, an AR experience is selected to satisfy it or aid in its satisfaction. 


\section{Augmented Reality}

\section{Need Identification}

\section{Logic}

\section{Sensor Data}

Figure 3. Layers of functionality in the proposed application.

The focus in the present research is on how needs trigger AR rather than how AR satisfies a need. Nevertheless, it is essential to indicate that the augmented information in a user's environment is the possible satisfiers for the specific need that triggered the AR experience. For example, a satisfier for a hunger need may be the directions to the nearest restaurant to the user, or instructions on appropriate meal suggestions for a diabetic user. The satisfaction of needs in developing AR could be the responsibility of experience developers and marketers, and the selection of the relevant satisfier depends greatly on the user profile. Further explanation on needs and satisfiers is present in Section 3.4.

\subsection{Need Analysis}

Capturing human needs in a measurable form is a complex endeavor. Therefore, it requires extensive study and analysis. In this research, Max-Neef's human scale development theory and the proposed human needs matrix [36] (Table 5) are used as a guideline to explore the various needs and dissect them into measurable elements. The human needs matrix below presents examples of satisfiers for each need category, it is not exhaustive, further explanation and guidance on satisfiers are present in the human scale development book [36]. Furthermore, the Need Context Technology (NCT) framework (Table 6) [37] is used to map relations and tools in the analysis. The aim is to study the technology that supports need detection, starting with the most basic measurable needs (usually related to health readings, hunger, stress) and evolving into the most complex needs.

The emphasis in this work is on human needs as triggers for an AR experience. Hence the goal is to provide the logic to respond to situations such as this example:

- If a user has a subsistence need on a Being axis, trigger experience A.

This statement leads to the following questions:

- What elements define a need?

- How to measure a need?

Figure 4 describes the relationships between the main elements of the proposed model as follows:

- A person has a need.

- A need has one of three triggers: homeostasis imbalance, incentive, or stimulation.

- A need has a satisfier, which has an AR experience.

- A context describes the state of a person and can be an external state (environmental) or the internal state of a user.

- An external environmental state can be an incentive that triggers a need.

- An internal state can reflect a homeostasis imbalance that triggers a need. 
Table 5. Human needs matrix [38].

\begin{tabular}{|c|c|c|c|c|}
\hline $\begin{array}{l}\text { Needs According } \\
\text { to Axiological } \\
\text { Categories }\end{array}$ & Being & Having & Doing & Interacting \\
\hline Subsistence & 1/Physical health, mental health, & \multirow{3}{*}{$\begin{array}{c}\text { 2/Food, shelter, work } \\
\text { 6/insurance systems, savings, work, } \\
\text { 10/Friendship, family, partnerships, a } \\
\text { sense of humor }\end{array}$} & 3/Feed, procreate, rest, work & 4/Living environment, social setting \\
\hline Protection & 5/Care, adaptability, autonomy & & $7 /$ prevent, plan, take care of, cure, help & 8/Living space, social environment, \\
\hline Affection & 9/Self-esteem, solidarity, respect & & 11/Caress, express emotions & 12/Privacy, intimacy, home \\
\hline Understanding & $\begin{array}{l}\text { 13/Critical conscience, curiosity, } \\
\text { receptiveness }\end{array}$ & $\begin{array}{l}\text { 14/Literature, teachers, method, } \\
\text { educational policies }\end{array}$ & $\begin{array}{l}\text { 15/Investigate, study, experiment, } \\
\text { educate, analyze, meditate }\end{array}$ & $\begin{array}{l}\text { 16/Settings of formative interaction, } \\
\text { schools, universities }\end{array}$ \\
\hline Leisure & $\begin{array}{c}\text { 21/Curiosity, receptiveness, } \\
\text { imagination }\end{array}$ & $\begin{array}{l}\text { 22/Games, spectacles, clubs, parties, } \\
\text { peace of mind, a sense of humor }\end{array}$ & 23/Day-dream, brood, dream & $\begin{array}{c}\text { 24/Privacy, intimacy, spaces of } \\
\text { closeness }\end{array}$ \\
\hline Creation & 25/Passion, determination, intuition & 26/Abilities, skills, method, work & $\begin{array}{l}\text { 27/Work, invent, build, design, } \\
\text { compose, interpret }\end{array}$ & $\begin{array}{c}\text { 28/Productive and feedback settings, } \\
\text { workshops }\end{array}$ \\
\hline Identity & 29/Sense of belonging, consistency & $\begin{array}{c}\text { 30/Symbols, language, religions, habits, } \\
\text { customs, }\end{array}$ & $\begin{array}{c}\text { 31/Commit oneself, integrate oneself, } \\
\text { confront }\end{array}$ & 32/Social rhythms, everyday settings, \\
\hline Freedom & $\begin{array}{l}\text { 33/Autonomy, self-esteem, } \\
\text { determination }\end{array}$ & $34 /$ Equal rights & 35/Dissent, choose, be different from & 36/Temporal/Spatial plasticity \\
\hline
\end{tabular}

Table 6. Need-context-technology framework [37].

\begin{tabular}{|c|c|c|c|c|}
\hline $\begin{array}{l}\text { Fundamental Human Needs } \\
\text { Existential Categories }\end{array}$ & $\begin{array}{c}\text { Being } \\
\text { (Qualities) }\end{array}$ & $\begin{array}{l}\text { Having } \\
\text { (Things) }\end{array}$ & $\begin{array}{l}\text { Doing } \\
\text { (Actions) }\end{array}$ & $\begin{array}{l}\text { Interacting } \\
\text { (Settings) }\end{array}$ \\
\hline $\begin{array}{l}\text { Context-Aware } \\
\text { Categorization }\end{array}$ & User, Who (Identity) & Things & $\begin{array}{l}\text { What (Activity) } \\
\text { When (Time) }\end{array}$ & Where (Location), Weather, Social, Networking \\
\hline Sensors and Technology & $\begin{array}{l}\text { Emotion Sensors } \\
\text { Body Sensors }\end{array}$ & IoT systems and Sensors & Activity recognition through motion sensors & $\begin{array}{l}\text { Location awareness, nearby user device (for } \\
\text { proximity with other users) }\end{array}$ \\
\hline
\end{tabular}




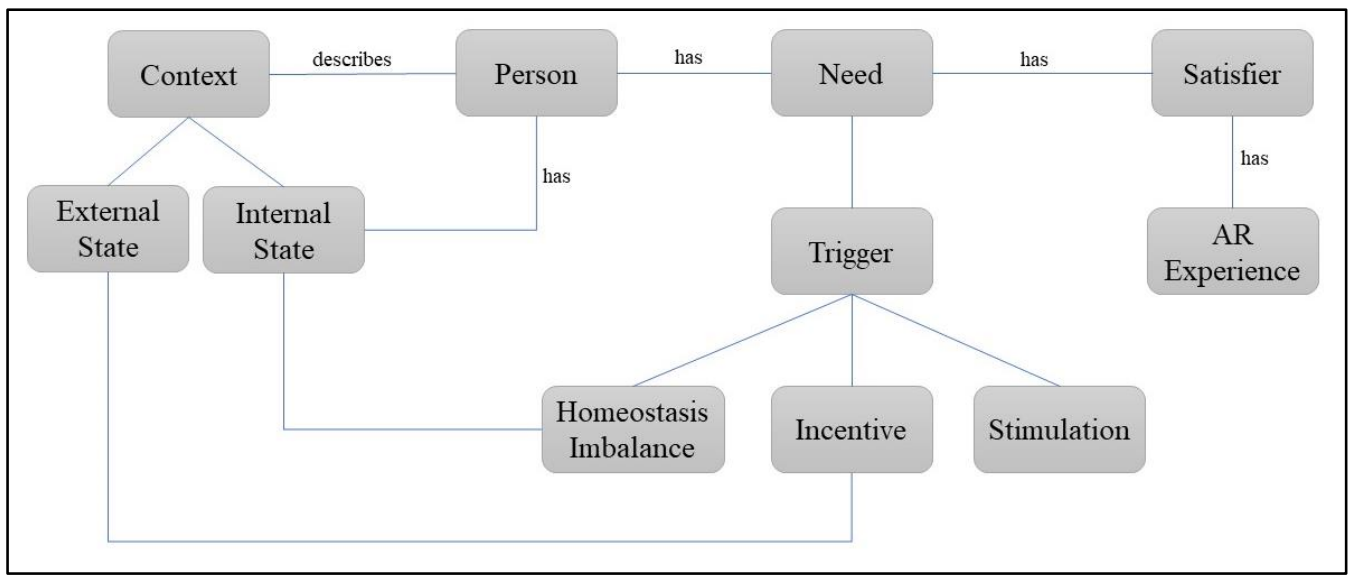

Figure 4. Conceptual model of augmented reality for human needs [39].

A trigger in psychology is a factor that activates a need. There are three types of needs triggers [40]:

- Homeostasis Imbalance: is the internal state that reflects a malfunction in the body processes resulting in a rise of a need. (internal)

- Incentive: is an external positive or negative environmental stimulus that motivates a person. (external)

- Stimulation: is an activity that causes excitement or pleasure.

Connecting these triggers (Figure 5) with the basic needs and the related technology (Table 6) forms the foundation for detecting a human need and establishing a need as a trigger for an AR experience.

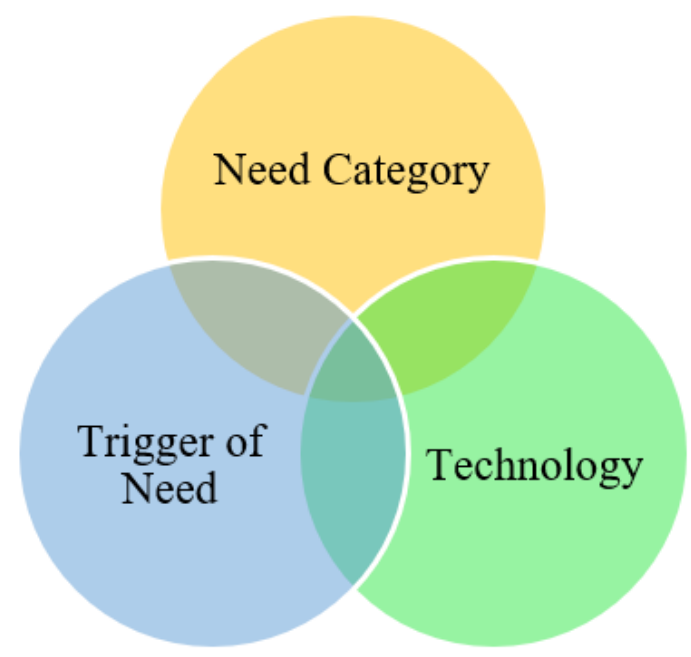

Figure 5. Components for human needs detection.

\subsection{Needs to Sensor Analysis}

This section connects the various needs with currently available sensors. To establish the connection, first, the identification of the major categories of needs triggers: internal and external is presented (Figure 6). The internal type relates to a user's body readings, including homeostasis, emotions, and stimulation. While the external relates to the surroundings and the environment, incentives, context, habits, and stimulation, these categories also apply to the sensor types. Specific body and wearable sensors can be used for internal triggers, such as Wearable Health Systems (WHS) or Wearable Biomedical Systems (WBS) [41]. These are termed non-invasive measuring devices that provide continuous 
monitoring. The external triggers relate to context and environmental sensors, including location, temperature, lighting conditions, and sound.
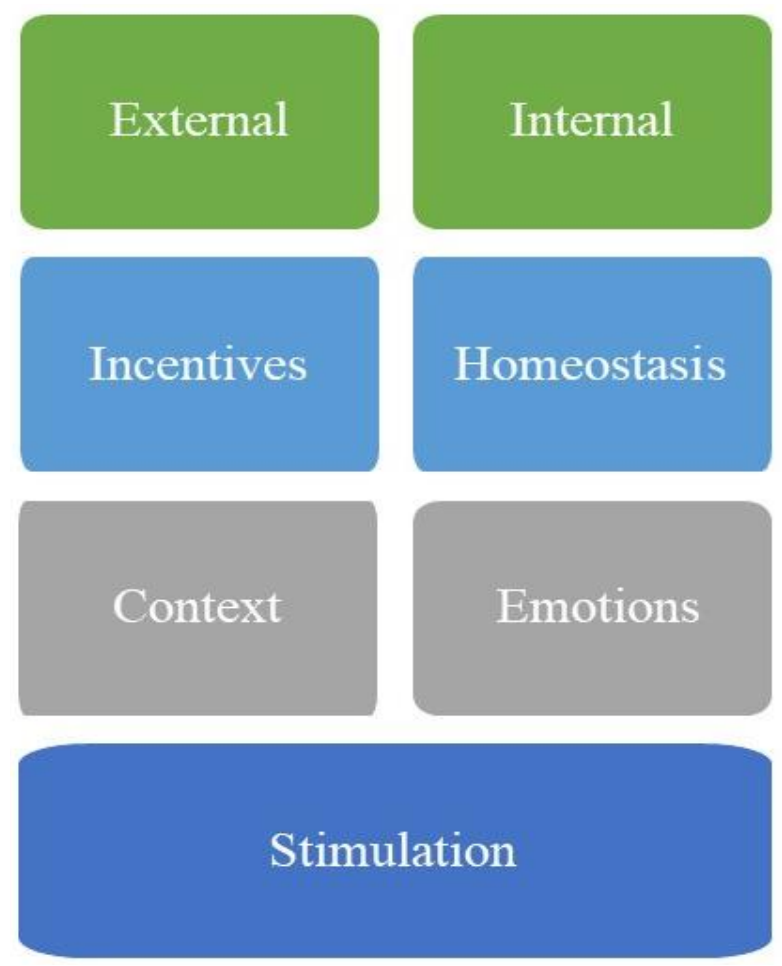

Figure 6. External and Internal Needs.

\section{Materials and Methods}

This section introduces the developed methodology to present the concept of a NeedsBased Trigger for Augmented Reality. It details an example scenario to explain the needsbased AR experience, followed by an application process and a proof of concept prototype.

\subsection{Scenario Analysis}

A scenario is a "hypothetical story used to help a person think through a complex problem or system" [42]. The intention is to use the scenario as an example to explain the use of the model.

For this scenario, the decision is to use the subsistence need on the being axis. Basic subsistence needs include the need for food, water, and accommodation. Therefore, the $A R$ experience developer decides that: when a user is hungry, trigger experience $A$, an advertisement for the nearby restaurant.

Analyzing this scenario, it is possible to have one of these cases:

1. There is a homeostatic need for food.

2. There is a regular habit of eating at a specific time.

3. There is an external incentive that excites the user to have food.

The homeostatic need requires special sensors to detect the production of the ghrelin hormone or a low blood glucose level that indicates energy scarcity and hunger and triggers the experience. The habit may be predicted from previous user activity; therefore, at a particular time every day, the user needs to eat, and the system predicts that and presents the AR experience. Detecting context information leads to identifying possible incentives that might cause hunger, offering an AR experience in this situation, and asking for feedback can enhance the process of detection and trigger initiation. 


\subsection{Application Process}

Based on the previous scenario, the following application process is developed (Figure 7). The process starts with selecting the sensor data, analyzing the data, followed by predictions that lead to triggering the AR experience. Afterward, collecting user feedback enhances the analysis and prediction stages. To test this application process, a prototype architecture is suggested (Figure 8). The architecture is composed of the frontend user interface and the backend experience developer interface. The developer decides the need for which he/she develops the AR experience. Then collects relevant content in the form of audio, image, 3D objects, or animation. Then, the designer designs and produces the experience. These experiences are then saved in the platform database. The user frontend initiates by creating a user profile and collecting all basic user information. The application then collects continuous sensor data and analyzes possible needs. The analysis can result in a need-based recognition or prediction. Based on the identified need, an AR experience is recommended and displayed to the user.

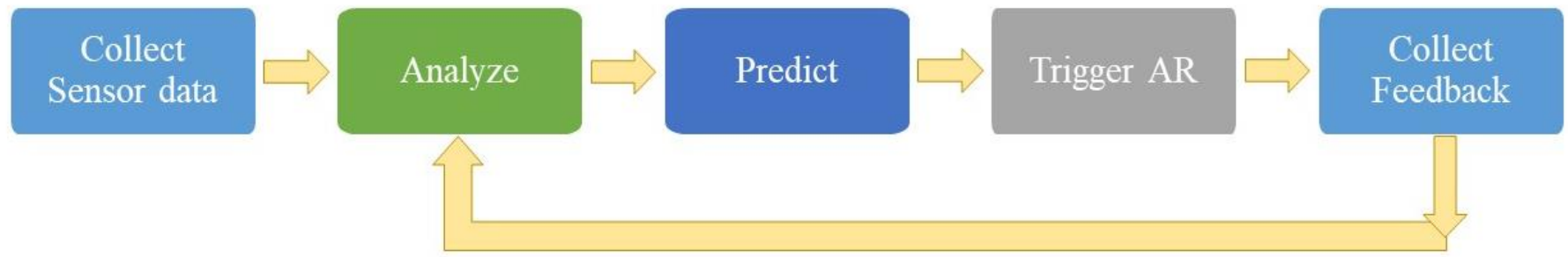

Figure 7. Application Process.

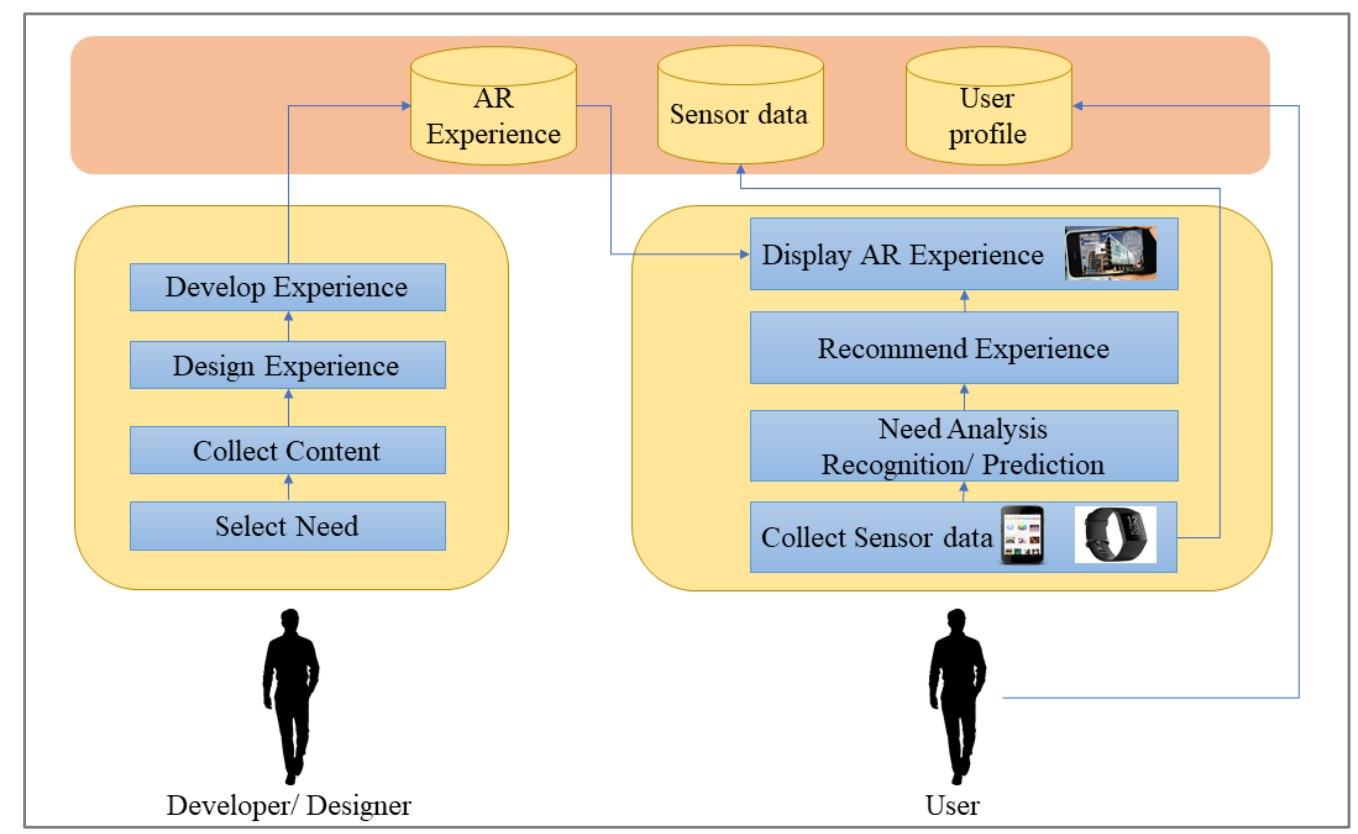

Figure 8. Testing prototype architecture.

\subsection{A Proof of Concept Prototype}

Concurrent research provides an extensive explanation of the triggers, sensors, and data requirements for the needs-based AR concept. As a result, it presents suggested guidelines to develop a needs-based AR system matching the concepts in Figures 7 and 8 . The nine guidelines may be generalized to all needs in the fundamental human needs matrix beyond the basic needs discussed in this study. While the prior research focused on data analysis and need prediction, this study has a goal to connect all the elements and present a connected concept demonstrating the complete application process. These guidelines are 
seen from the developer/designer's point of view. Following are the guidelines listed and exhibited for a prototype study.

1. Decide on the need you plan to satisfy with the AR experience.

The case study is a restaurant business that satisfies the subsistence needs of hunger and thirst. The goal is to trigger the AR experience that interests the individual to visit the restaurant at the detection of the subsistence need.

2. Determine needs specific elements and requirements (context, personas, type)

The subsistence need is dependent on internal and external contexts. Internal context represents the homeostasis imbalance of low blood glucose or dehydration. External context includes time, day, location, activity, and settings. The personas considered for this case are healthy individuals with no food allergies, and the type is needs-based triggered AR experience.

3. Select the trigger (homeostasis imbalance, habits, or incentives).

Developing a collective experience requires the use of all triggers; however, to simplify the process, this case selects the use of habits trigger. The habits trigger requires the collection of several records for accurate need prediction. The records must include basic profile information in addition to context information, activity, and current need.

4. Develop the AR experience with multiple options and preferences for that particular need.

This step aims to create an AR experience that targets particular needs and matches the business goals of the experience creator. Examples of such experiences (Figure 9) are retrieved from the menu AR application [43], and the SeeFood Augmented Reality Menu [44].

In the database, the AR experience should be paired with restaurant information such as restaurant name, location, cuisine, description, and such to create a point of interest and map directions for the individual.

5. Based on the need and trigger, select the appropriate sensors required to collect data.

Since subsistence is the selected need and habits constitute the trigger, the required sensors must capture the following data: time, day, activity, location, and proximity with others. The use of a mobile device allows for capturing the time, day, GPS location (identified by the user as home, restaurant, or other), and proximity with others (identified by the user as being with family, friend, or no one).

6. Collect data and build a user profile and database.

A sample of the database records representing the required data fields is presented in Figure 10. These records are extracted from the Context-Aware Personalization for Augmented Reality (CAP-AR) dataset [37].

7. Decide and develop the analysis mechanism (a rule engine, predictive algorithms).

The analysis mechanism of choice for the subsistence need based on habits are predictive algorithms. This choice is because habits are usually repetitive, and it is possible to train an algorithm to recognize them having enough records in the dataset. The analysis mechanism should detect the occurrence of a basic human need (trigger) and initiates the recommendation process, to present the individual with related AR experience.

8. Apply a recommendation process to select the AR experience specific to the individual's preferences.

In the case of needs-based AR applications, embodying context awareness is essential in the recommendation process. Therefore, the choice of a context-aware collaborative filtering algorithm [45] fits the criteria of such an application. This algorithm enables recommendations based on other similar users' feedback in addition to considering the current context of the user. 
9. Design a feedback collection method to improve recommendations.

After displaying the AR experience to the user, a user rating of the experience and satisfaction level should be recorded. User feedback aids in the creation of a ranking system that supports collaborative filtering recommendations.

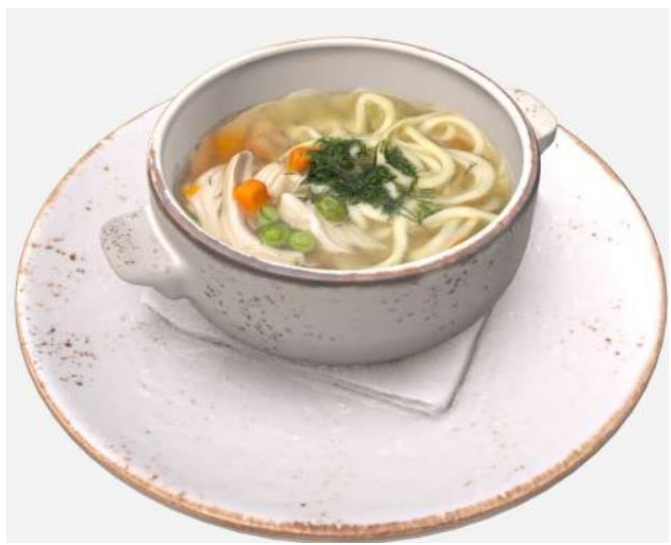

(a)

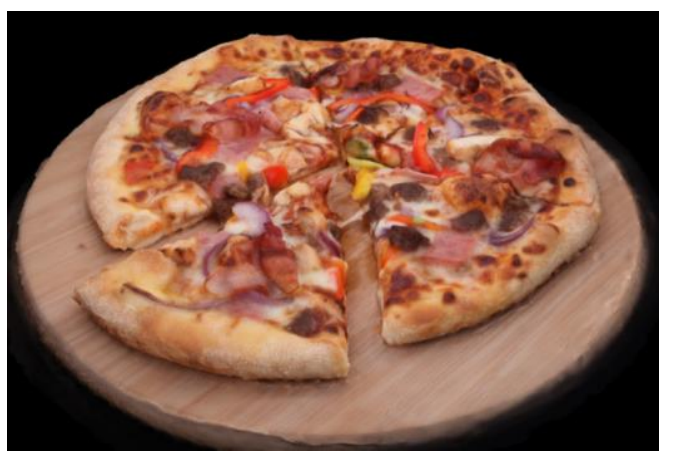

(c)

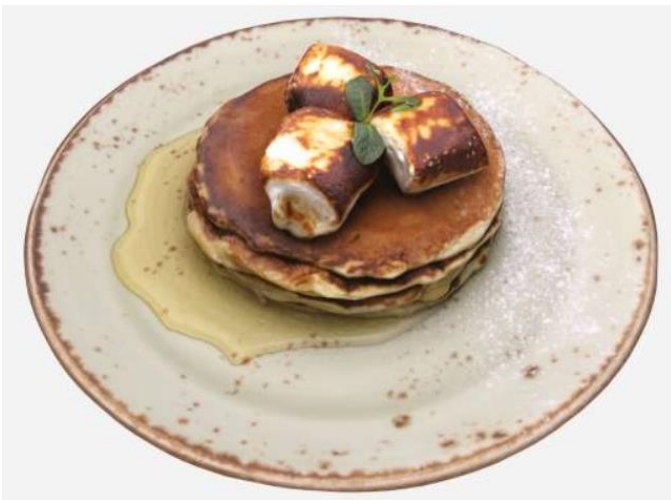

(e)

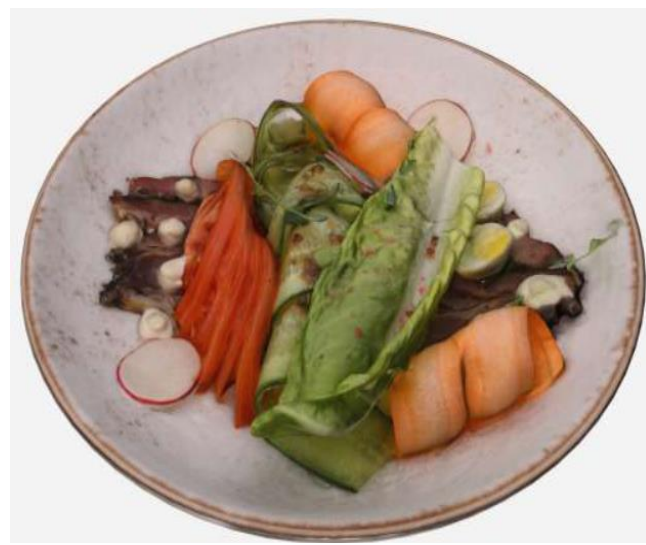

(b)

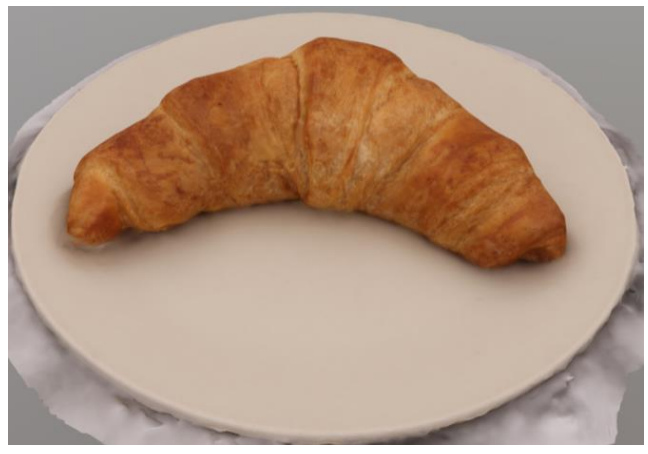

(d)

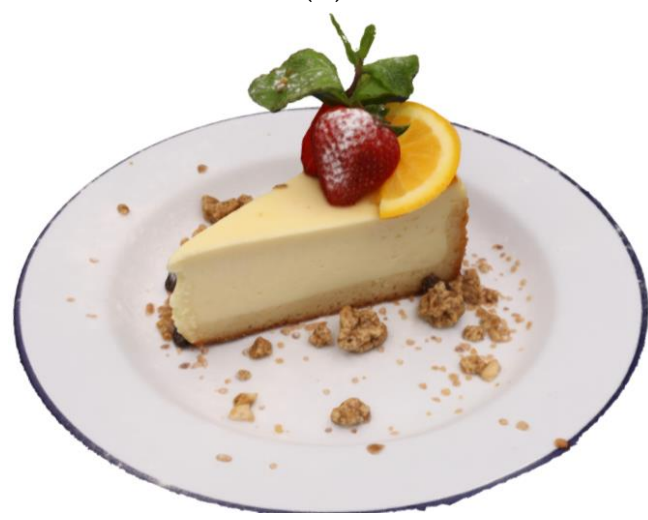

(f)

Figure 9. 3D models for AR subsistence need hunger experiences. Source: $(\mathbf{a}, \mathbf{b}, \mathbf{e})[43],(\mathbf{c}, \mathbf{d}, \mathbf{f})[44]$. 


\begin{tabular}{|c|c|c|c|c|c|c|c|c|c|c|c|}
\hline User Id & Weekday & In gener... & How do you descri... & How w... & Overall, how is y... & Submitted Ti... & Location: W... & Activity: Wh... & Are you ... & Stress: ... & Emotion: ... \\
\hline P11 & Thu & Good & No physical activities & Cool & a bad mood & EVENING & Car & NO_ANSWER & Family & Moderate & Fine \\
\hline P11 & Fri & Very Good & No physical activities & Cool & a very good mood & MORNING & Home & Nap/Resting & No one & Low & Peaceful \\
\hline P11 & Fri & Very Good & No physical activities & Cool & a very good mood & AFTERNOON & Home & Doing House... & Family & Low & Happy \\
\hline P11 & Fri & Very Good & No physical activities & Cool & a very good mood & AFTERNOON & Home & Relaxing & No one & Low & Fine \\
\hline P11 & Fri & Very Good & No physical activities & Cool & a very good mood & EVENING & Home & Eating & Family & Low & Happy \\
\hline P11 & Sat & Very Good & No physical activities & Cool & a very good mood & MORNING & Home & Relaxing & No one & Low & Fine \\
\hline P11 & Sat & Very Good & No physical activities & Cool & a very good mood & AFTERNOON & Home & Doing House... & No one & Moderate & Frustrated ... \\
\hline P11 & Sat & Very Good & No physical activities & Cool & a very good mood & AFTERNOON & Shopping Mall & Shopping & No one & Low & Excited \\
\hline P11 & Sat & Very Good & No physical activities & Cool & a very good mood & EVENING & Home & Doing House... & No one & Moderate & Happy \\
\hline P11 & Sun & Very Good & No physical activities & Warm & mildly pleasant ... & AFTERNOON & Home & Nap/Resting & No one & Low & Peaceful \\
\hline P11 & Sun & Very Good & No physical activities & Warm & mildly pleasant ... & AFTERNOON & Home & Doing House... & Family & Low & Happy \\
\hline P11 & Sun & Very Good & No physical activities & Warm & mildly pleasant ... & AFTERNOON & Home & Doing House... & No one & High & Frustrated ... \\
\hline P11 & Sun & Very Good & No physical activities & Warm & mildly pleasant ... & EVENING & Home & Eating & No one & Moderate & Fine \\
\hline P11 & Mon & Very Good & No physical activities & Warm & mildly pleasant ... & AFTERNOON & Home & Nap/Resting & No one & Low & Tired \\
\hline P11 & Mon & Very Good & No physical activities & Warm & mildly pleasant ... & AFTERNOON & Home & Eating & No one & Low & Overwhel... \\
\hline P11 & Mon & Very Good & No physical activities & Warm & mildly pleasant ... & EVENING & Home & Doing House... & No one & Extreme & Frustrated ... \\
\hline P11 & Mon & Very Good & No physical activities & Warm & mildly pleasant ... & NIGHT & Home & Studying & No one & Moderate & Overwhel... \\
\hline
\end{tabular}

Figure 10. Records of the dataset portraying required fields.

\section{Results}

Section 4.3 presents a prototype case study that demonstrates the Needs-based AR application. The principal findings of the case study are that the transfer from sensor data to meaningful information requires appropriate convergence methods since constantly requesting information from the individual may decrease pervasiveness. Since human behavior is changing, following a clear pattern on certain days and changing the behavior in others, it is essential to have sufficient records to apply machine learning algorithms and produce correct predictions. Applying the predictive algorithms to predict needs for a certain persona (User Id: P11) in the CAP-AR dataset produced the results in Table 7.

Table 7. Need prediction results.

\begin{tabular}{cccc}
\hline Algorithm & $\begin{array}{c}\text { Accuracy of all } \\
\text { Needs Prediction }\end{array}$ & $\begin{array}{c}\text { Eat/Drink Need } \\
\text { Class Precision }\end{array}$ & $\begin{array}{c}\text { Eat/Drink Need } \\
\text { Class Recall }\end{array}$ \\
\hline Decision Tree & $49.32 \%$ & $44.44 \%$ & $42.11 \%$ \\
Random Forest & $32.88 \%$ & $40.00 \%$ & $21.05 \%$ \\
Naive Bayes & $38.36 \%$ & $42.11 \%$ & $42.11 \%$ \\
\hline
\end{tabular}

\section{Discussion}

The present research explores the technologies and classification of augmented reality. To provide personalized AR experiences, it connects the concept of AR with that of human needs. In this case, the human need is considered to be the trigger of the AR experience.

The needs prediction results from the CAP-AR dataset show low accuracy for the Eat/Drink subsistence need, this is due to the varying context information associate with one certain need. Basic human needs may occur at different times and contexts, correct prediction of needs requires an ample number of records in the dataset

Despite the low accuracy of the prediction results, the guidelines demonstrate a coherent means to develop a needs-based AR application that should be further tested.

While a need is a primary controller of the experience trigger, it might stir an argument: if a user has deficiencies in basic human needs, what makes the user capable of possessing the technology to operate the experience? This question might be answered in two folds: 
- Technology is now reaching many people in various living conditions.

- People undergo changing levels of needs daily regardless of capabilities.

- AR experiences are custom-made for specific reasons; however, these reasons are usually generic and not user-related, even in the case of personalized AR, the experiences are product, location, or service related more than user related. This research questions that from a plethora of AR experiences that shall be available in the future, how do we make AR more user-specific and find the best experience for a user at a certain time? This study answers this question by incorporating basic human needs into the equation. Therefore, the novelty is in connecting the concepts of augmented reality, needs detection, and satisfier recommendation.

The goal of this research is to create the means to trigger the experience based on needs. However, the actual design and the AR experience's purpose are left to the creators and designers of the experience.

\section{Conclusions}

To realize needs-based augmented reality, it is essential to capture the different needs using computing methods. In this paper, the focus is on the automatic detection of basic needs. A theoretical framework is proposed that combines augmented reality with human needs to realize the process of needs-based AR.

First, a summary of technologies and classifications of AR is provided. A review of existing platforms is also provided.

Second, a discussion on a theoretical framework leading to the foundation of the proposed concept. This is followed by a need and sensor analysis.

Third, a scenario is presented to demonstrate the proposed concept, followed by the application process based on the scenario and a proof of concept prototype.

To use human needs as triggers in augmented reality applications is significant and necessary in various domains. For pervasive computing, the combination expands the variety of research and enables the personalization of experiences. This research is also practical in marketing, entertainment, and ambient assisted living. The proposed framework established based on previous research, focuses on needs analysis, while the guidelines provide a roadmap to create a needs-based AR application. Future work will concentrate on system implementation with a vision of achieving needs-based AR.

Author Contributions: Conceptualization, M.A.Y., and A.D.; methodology, M.A.Y.; formal analysis, M.A.Y.; data curation, M.A.Y.; writing-original draft preparation, M.A.Y.; writing-review and editing, A.D.; visualization, M.A.Y.; supervision, A.D. All authors have read and agreed to the published version of the manuscript.

Funding: This research received no external funding.

Institutional Review Board Statement: Not applicable.

Informed Consent Statement: Not applicable.

Data Availability Statement: Data available on request due to privacy restrictions.

Conflicts of Interest: The authors declare no conflict of interest.

\section{References}

1. Ronald, T.; Azuma, A. Survey of augmented reality. Presence Teleoper. Virtual Environ. 1997, 6, 355-385. [CrossRef]

2. Carmigniani, J.; Furht, B.; Anisetti, M.; Ceravolo, P.; Damiani, E.; Ivkovic, M. Augmented reality technologies, systems and applications. Multimed. Tools Appl. 2011, 51, 341-377. [CrossRef]

3. Azuma, R.; Baillot, Y.; Behringer, R.; Feiner, S.; Julier, S.; MacIntyre, B. Recent advances in augmented reality. IEEE Comput. Graph. Appl. 2001, 21, 34-47. [CrossRef]

4. Dunleavy, M.; Dede, C. Augmented reality teaching and learning. In Handbook of Research on Educational Communications and Technology; Springer: Cham, Switzerland, 2014; pp. 735-745. 
5. Patricio, J.M.; Costa, M.C.; Carranca, J.A.; Farropo, B. SolarSystemGO-An augmented reality based game with astronomical concepts. In Proceedings of the 2018 13th Iberian Conference on Information Systems and Technologies (CISTI), Caceres, Spain, 13-16 June 2018; IEEE: Piscataway, NJ, USA, 2018; pp. 1-3.

6. Waltner, G.; Schwarz, M.; Ladstätter, S.; Weber, A.; Luley, P.; Bischof, H.; Lindschinger, M.; Schmid, I.; Paletta, L. Mango-mobile augmented reality with functional eating guidance and food awareness. In Lecture Notes in Computer Science, Proceedings of the International Conference on Image Analysis and Processing, Genoa, Italy, 7-8 September 2015; Springer: Cham, Switzerland, 2015; pp. 425-432.

7. Khor, W.S.; Baker, B.; Amin, K.; Chan, A.; Patel, K.; Wong, J. Augmented and virtual reality in surgery-the digital surgical environment: Applications, limitations and legal pitfalls. Ann. Translat. Med. 2016, 4, 454. [CrossRef]

8. Frigo, M.A.; da Silva, E.C.; Barbosa, G.F. Augmented reality in aerospace manufacturing: A review. J. Ind. Intell. Inform. 2016, 4, 125-130. [CrossRef]

9. Hammady, R.; Ma, M.; Temple, N. Augmented reality and gamification in heritage museums. In Lecture Notes in Computer Science, Proceedings of the Joint International Conference on Serious Games, Brisbane, QLD, Australia, 26-27 September 2016; Springer: Cham, Switzerland, 2016; pp. 181-187.

10. Boy, G.A.; Platt, D. A situation awareness assistant for human deep space exploration. In Lecture Notes in Computer Science, Proceedings of the International Conference on Human-Computer Interaction, Las Vegas, NV, USA, 21-26 July 2013; Springer: Cham, Switzerland, 2013; pp. 629-636.

11. Han, D.; tom Dieck, M.C.; Jung, T. User experience model for augmented reality applications in urban heritage tourism. J. Herit. Tour. 2018, 13, 46-61. [CrossRef]

12. Zhou, F.; Duh, H.B.; Billinghurst, M. Trends in augmented reality tracking, interaction and display: A review of ten years of ISMAR. In Proceedings of the 2008 7th IEEE/ACM International Symposium on Mixed and Augmented Reality, Cambridge, UK, 15-18 September 2008; IEEE: Piscataway, NJ, USA, 2008; pp. 193-202.

13. Human, S.; Fahrenbach, F.; Kragulj, F.; Savenkov, V. Ontology for Representing Human Needs, Knowledge Engineering and Semantic Web; Różewski, P., Lange, C., Eds.; Springer International Publishing: Cham, Switzerland, 2017; pp. $195-210$.

14. Livingston, M.A. Evaluating human factors in augmented reality systems. IEEE Comput. Graph. Appl. 2005, 25, 6-9. [CrossRef]

15. Juan, C.; YuLin, W.; Wei, S. Construction of interactive teaching system for course of mechanical drawing based on mobile augmented reality technology. Int. J. Emerg. Technol. Learn. 2018, 13, 126.

16. Kim, K.; Billinghurst, M.; Bruder, G.; Duh, H.B.; Welch, G.F. Revisiting trends in augmented reality research: A review of the 2nd decade of ISMAR (2008-2017). IEEE Trans. Vis. Comput. Graph. 2018, 24, 2947-2962. [CrossRef]

17. Gamper, H. Enabling Technologies for Audio Augmented Reality Systems. Ph.D. Thesis, Aalto University, Espoo, Finland, 2014.

18. Edwards-Stewart, A.; Hoyt, T.; Reger, G. Classifying different types of augmented reality technology. Ann. Rev. CyberTher. Telemed. 2016, 14, 199-202.

19. Ribeiro, F.; Florêncio, D.; Chou, P.A.; Zhang, Z. Auditory augmented reality: Object sonification for the visually impaired. In Proceedings of the IEEE 14th International Workshop on Multimedia Signal Processing (MMSP), Banff, AB, Canada, 17-19 September 2012; IEEE: Piscataway, NJ, USA, 2012; pp. 319-324.

20. Jeon, S.; Choi, S. Haptic augmented reality: Taxonomy and an example of stiffness modulation. Presence Teleoper. Virtual Environ. 2009, 18, 387-408. [CrossRef]

21. Narumi, T.; Nishizaka, S.; Kajinami, T.; Tanikawa, T.; Hirose, M. Augmented Reality Flavors: Gustatory Display Based on Edible Marker and Cross-Modal Interaction. In Proceedings of the SIGCHI Conference on Human Factors in Computing Systems, Vancouver, BC, Canada, 7-12 May 2011; Association for Computing Machinery: New York, NY, USA, 2011; pp. 93-102.

22. Yamada, T.; Yokoyama, S.; Tanikawa, T.; Hirota, K.; Hirose, M. Wearable Olfactory Display: Using Odor in Outdoor Environment. In Proceedings of the IEEE Virtual Reality Conference (VR 2006), Alexandria, VA, USA, 25-29 March 2006; pp. 199-206.

23. Bower, M.; Howe, C.; McCredie, N.; Robinson, A.; Grover, D. Augmented Reality in education-Cases, places and potentials. Educ. Media Int. 2014, 51, 1-15. [CrossRef]

24. He, Z.; Wu, L.; Li, X.R. When art meets tech: The role of augmented reality in enhancing museum experiences and purchase intentions. Tour. Manag. 2018, 68, 127-139. [CrossRef]

25. Serravalle, F.; Ferraris, A.; Vrontis, D.; Thrassou, A.; Christofi, M. Augmented reality in the tourism industry: A multi-stakeholder analysis of museums. Tour. Manag. Perspect. 2019, 32, 100549. [CrossRef]

26. Billinghurst, M. Augmented reality in education. New Horiz. Learn. 2002, 12, 1-5.

27. Chen, P.; Liu, X.; Cheng, W.; Huang, R. A review of using Augmented Reality in Education from 2011 to 2016. In Innovations in Smart Learning; Springer: Cham, Switzerland, 2017; pp. 13-18.

28. Fan, H.; Poole, M.S. What is personalization? Perspectives on the design and implementation of personalization in information systems. J. Organ. Comput. Electr. Commer. 2006, 16, 179-202.

29. Zimmermann, A.; Specht, M.; Lorenz, A. Personalization and context management. User Model. User Adapt. Interact. 2005, 15, 275-302. [CrossRef]

30. Paavilainen, J.; Korhonen, H.; Alha, K.; Stenros, J.; Koskinen, E.; Mayra, F. The Pokémon GO experience: A location-based augmented reality mobile game goes mainstream. In Proceedings of the 2017 CHI Conference on Human Factors in Computing Systems, Denver, CO, USA, 6-11 May 2017; pp. 2493-2498. 
31. Tahara, T.; Seno, T.; Narita, G.; Ishikawa, T. Retargetable AR: Context-aware Augmented Reality in Indoor Scenes based on 3D Scene Graph. In Proceedings of the 2020 IEEE International Symposium on Mixed and Augmented Reality Adjunct (ISMAR-Adjunct), Recife, Brazil, 9-13 November 2020; IEEE: Piscataway, NJ, USA, 2020; pp. 249-255.

32. Ghadiri, N.; Nematbakhsh, M.A.; Baraani-Dastjerdi, A.; Ghasem-Aghaee, N. A Context-Aware Service Discovery Framework Based on Human Needs Model, Service-Oriented Computing-ICSOC 20-07; Krämer, B.J., Lin, K., Narasimhan, P., Eds.; Springer: Berlin/Heidelberg, Germany, 2007; pp. 404-409.

33. Abramovich, A. Theory of needs and problems. Socio Econ. Sci. 2020, 4, 411.

34. Zhu, Y.; Chen, H. Social media and human need satisfaction: Implications for social media marketing. Bus. Horiz. 2015, 58, 335-345. [CrossRef]

35. Houghton, D.; Pressey, A.; Istanbulluoglu, D. Who needs social networking? An empirical enquiry into the capability of Facebook to meet human needs and satisfaction with life. Comput. Hum. Behav. 2020, 104, 106153. [CrossRef]

36. Max-Neef, M.A. Human Scale Development; Apex Press: New York, NY, USA, 1991.

37. Yahya, M.; Dahanayake, A. A Needs-based personalization model for context aware applications. Front. Artif. Intell. Appl. 2016, 292, 63-82.

38. Max-Neef, M.; Elizalde, A.; Hopenhayn, M. Development and human needs. In Real-Life Economics: Understanding Wealth Creation; Routledge: London, UK, 1992; pp. 197-213.

39. Yahya, M.A.; Dahanayake, A. Augmented reality for human needs: An ontology. Front. Artif. Intell. Appl. 2020, 333, $275-294$.

40. Myers, D.G. Psychology, 10th ed.; Worth Publishers: New York, NY, USA, 2013.

41. Andreoni, G.; Standoli, C.E.; Perego, P. Defining requirements and related methods for designing sensorized garments. Sensors 2016, 16, 769. [CrossRef] [PubMed]

42. Cem Kaner, J.D. An Introduction to Scenario Testing; Florida Institute of Technology: Melbourne, Australia, 2013 ; pp. 1-13.

43. Menu, A.R. Look at Food in a New Way. Available online: http:/ / menuar.ru/en.php (accessed on 18 July 2021).

44. See Food Augmented Reality Menu. Available online: https://sketchfab.com/seefood (accessed on 18 July 2021).

45. Chen, A. Context-Aware Collaborative Filtering System: Predicting the User's Preference in the Ubiquitous Computing Environment, Location-and Context-Awareness; Strang, T., Linnhoff-Popien, C., Eds.; Springer: Berlin/Heidelberg, Germany, 2005 ; pp. $244-253$. 